\title{
Usefulness of Blood Pressure Measurement by Community Pharmacists in the Management of Hypertension
}

\author{
Daniel Sabater-Hernández, PharmD, PhD; José Sendra-Lillo, PharmD, PhD; \\ María José Faus, PharmD, PhD; Fernando Martínez-Martínez, PharmD, PhD; \\ and Alejandro de la Sierra, MD, PhD
}

$\mathrm{F}$ or decades, blood pressure (BP) measurement at a physician's office has been considered the cornerstone in the diagnosis and management of hypertension. However, BP measurement by a physician may induce an alerting reaction in the patient, which is manifest by a transient increase in BP, usually called the "white-coat effect" (WCE). ${ }^{1}$ WCE could possibly impair the appropriateness of clinical evaluations and decision making (e.g., overdiagnosis, underestimate of effectiveness, use of unnecessary medication).

It is important to differentiate between the WCE (isolated increase in BP, expressed in millimeters mercury [mm Hg]) and white-coat hypertension (WCH), defined as a condition in which office BP is persistently elevated (equal to or greater than $140 / 90 \mathrm{~mm} \mathrm{Hg}$ ), while out-of-office BP is within the normal range (less than 135/85 $\mathrm{mm} \mathrm{Hg}$ ). Thus, the WCE and WCH are different entities.

The problem of the WCE can be overcome with the use of out-of-office BP measurements, such as either ambulatory $\mathrm{BP}$ monitoring (ABPM) or home BP monitoring (HBPM). ${ }^{2}$ Compared with BP measurement at a physician's office, both ABPM and HBPM provide a greater number of BP readings in more realistic circumstances and may lead to an improved assessment of patients' "true" BP levels. Additionally, these approaches show a better correlation with target organ damage (e.g., carotid atherosclerosis) and better predict cardiovascular events, such as nonfatal myocardial infarction, nonfatal stroke, or death. ${ }^{3-5}$ Moreover, the ABPM register provides extensive information on several BP parameters, including average BP (daytime, nighttime, 24 hours), BP variability, morning BP surge, or nocturnal fall in BP, among others. For these reasons, ABPM, as the reference, and HBPM, as a complement, are currently considered valuable methods in the diagnosis and management of hypertension. ${ }^{2,6-9}$

Despite its usefulness, ABPM is not available for the entire hypertensive population. On the other hand, although HBPM is cheaper and more widely available than ABPM, this method may not be recommended in some situations, such as learning disability, risk of anxiety and excessive monitoring, risk of treatment changes without doctor's guidance, or questionable reliability of BP values reported by patients. In these cases, it would be desirable to have an alternative that can provide valuable information for clinical decision making.

Theoretically, BP measurement by community pharmacists presents certain key advantages, making it of particular interest. These advantages include (a) the availability of multiple BP readings due to the accessibility of the pharmacy and (b) the presence of a health care professional, who can select appropriate (clinically validated) measurement devices and supervise the measurement conditions. Moreover, patients commonly check BP at community pharmacies ${ }^{10}$ and taking BP measurements in this setting is recommended by some scientific hypertension societies, such as those in Canada (Canadian Hypertension Education Program Implementation Task Force) and Spain. ${ }^{11,12}$

Despite interest in the community pharmacy BP (CPBP) measurement method, we found in a literature review (SabaterHernández et al., 2010) that the usefulness of CPBP measurement in the diagnosis and treatment of hypertension had not been adequately studied. ${ }^{13}$ Therefore, it was not possible to set clear recommendations to guide decision making based on CPBP measurements. In order to further assess the clinical usefulness of this method, the systematic error with respect to other BP measurements obtained by the reference methods in the management of hypertension (ABPM, HBPM, or physician's office BP as the traditional method) should be analyzed through agreement studies. ${ }^{14,15}$ In brief, agreement studies are conducted to assess the concordance (through appropriate statistical tests) between 2 or more measurements provided by different/alternative methods. ${ }^{16}$

Since 2008, our research group has promoted a research line in this field. To date, we have reported results from 2 studies: the MEdida de la Presión Arterial en FARmacia (MEPAFAR) study and the Palmera study. ${ }^{1722}$ Both studies included treated hypertensive patients (diagnosed by a physician; $\mathrm{n}=169$ and $n=70$, respectively). In the MEPAFAR study, CPBP measurements were compared with HBP and daytime ABP, whereas in the Palmera study, CPBP was compared with HBP and physician's office BP (POBP).

Methods of the MEPAFAR and Palmera studies are described in previous publications. ${ }^{17-22}$ Briefly, CPBP was measured by the same pharmacist at each pharmacy ( 9 pharmacies were enrolled in both studies). In the MEPAFAR study, CPBP was recorded during 4 visits to the pharmacy over a 4 -week period. Patients' visits were scheduled at the same time for all 4 time points ( \pm 1 hour). In the Palmera study, CPBP was measured at 5 visits over a 5 -week period (at least 2 visits in the 
morning and 2 visits in the evening). POBP was measured by a physician during 3 visits (all of which were scheduled in the morning) over a 3-week period. At each pharmacy and physician's office visit, 3 measurements were taken. At home, patients monitored their BP over 4 consecutive working days, taking 3 measurements in the morning and 3 measurements in the evening. The clinically validated OMRON M10-IT automatic electronic device (Omron Corp, Tokyo, Japan) was used at home, at the physician's office, and in community pharmacies. The same automated device was used in all locations, including the physician's office, to maintain consistency among the readings, improve the comparisons among them, and avoid any potential bias. In addition, current medical practice is moving away from using conventional mercury sphygmomanometers, and automated oscillometric devices are becoming very popular and are being used in many medical centers in developed countries, including Spain. ${ }^{23,24}$ All pharmacists, physicians, and patients were previously instructed on how to properly perform BP measurements according to international guidelines. ${ }^{6}$ ABPM was performed on a working day. The average daytime ABP was calculated according to the sleep diary kept by each patient.

The main findings from both studies can be summarized as follows:

- The magnitude of the WCE was progressively reduced over successive visits to the community pharmacy. ${ }^{18}$ Overall, the community pharmacy WCE was negligible and significantly lower than that observed at the physician's office. ${ }^{18,20}$

- The agreement between CPBP and HBP was found acceptable (i.e., kappa coefficient was 0.62; Lin correlation-concordance coefficients [CCC] were 0.80 for both systolic BP and diastolic BP) ${ }^{17}$ On the other hand, the agreement with daytime ABP was only moderate (i.e., kappa coefficient was 0.56 ; CCCs were 0.74 and 0.67 for systolic BP and diastolic $\mathrm{BP}$, respectively). ${ }^{17}$

- The CPBP measurement method showed high specificity (MEPAFAR study: $98.0 \%$ and 91.8\%, using HBPM and daytime ABPM as the reference, respectively; Palmera study: 92.9\%, using HBPM as the reference) and positive predictive values (MEPAFAR study: $95.5 \%$ and $80.0 \%$, using HBPM and daytime ABPM as the reference, respectively; Palmera study: $85.0 \%$, using HBPM as the reference); thus, it was found to be accurate to confirm the presence of a lack of BP control. ${ }^{17,19}$ Based on these results, treated patients showing persistently elevated CPBP should be referred to a physician because they may require adjustments in their antihypertensive therapies.

- On the other hand, the CPBP measurement method showed low sensitivity (MEPAFAR study: 60.5\% and 61.0\%, using HBPM and daytime ABPM as the reference, respectively; Palmera study: $60.7 \%$, using HBPM as the reference) and negative predictive values (MEPAFAR study: $77.4 \%$ and
81.4\%, using HBPM and daytime ABPM as the reference, respectively; Palmera study: 78.0\%, using HBPM as the reference). ${ }^{17,19}$ As a result, the usefulness of the CPBP measurement method could be limited in patients showing adequate CPBP control; some of these patients may require treatment intensification (based on high daytime ABP and/or HBP figures) despite normal BP values at the community pharmacy.

- The CPBP measurement method showed a greater ability than HBPM to confirm the presence of elevated ABP (based on positive likelihood ratios). ${ }^{17}$

- The CPBP measurement method was superior to the POBP measurement method for detecting the presence of either control or a lack of control of HBP (based on positive and negative likelihood ratios for each method) ${ }^{19}$

To our knowledge, the MEPAFAR and Palmera studies provide evidence for the first time that helps to establish recommendations for community pharmacists and physicians when interpreting CPBP measurements in treated hypertensive patients. These recommendations are of particular interest due to the involvement of the community pharmacist in the followup of treated hypertensive patients ${ }^{25}$ and the need to achieve a better shared management of these patients.

As we mentioned above, ABPM and HBPM should be the first choice to assess the degree of BP control in the followup of hypertension. ${ }^{2,6-9}$ Therefore, community pharmacists should promote the use of these methods whenever possible. ${ }^{12}$ However, ABPM is not widely available in primary care practice, and not all patients are capable of measuring BP at home. Additionally, HBPM can cause unwanted reactions in some patients. Particularly in these cases, taking repeated BP measurements by community pharmacists may be the most suitable alternative to assess the effectiveness of antihypertensive treatment in clinical practice, even better than conventional POBP, which usually results in a higher measured BP. ${ }^{26}$ In our opinion, as a nearby health setting, the community pharmacy may offer a more comfortable environment than a physician's office. As a result, the patient's alerting reaction (WCE) in the community pharmacy becomes negligible; thus, the CPBP represents the true BP more accurately than does the POBP.

Based on its key advantages (i.e., lack of WCE, high accessibility of the community pharmacy, availability of multiple BP readings, and presence of a health care professional), we believe the CPBP measurement method should not be restricted to the specific cases already mentioned but should also be used routinely in clinical practice as an extension of POBP. Thus, when ABP and HBP readings are available, CPBP may be useful as complementary information to validate BP readings and help guide the titration of therapy.

We are aware that our data are a first step to establish the usefulness of the CPBP measurement method in the management of hypertension, and further research to assess the 
long-term agreement between methods, using larger samples, would be desirable. Also, a global assessment of this method would require studies measuring the association of CPBP with target organ damage and cardiovascular risk. To our knowledge, these studies have not been carried out but could accurately determine the specific usefulness of the CPBP measurement method in the management of hypertension. Moreover, during the interpretation and discussion of our results, we identified the following issues, which could guide and should be addressed in future studies:

- Patients included in the MEPAFAR and Palmera studies were all treated hypertensive patients. A parallel assessment of patients who are not undergoing treatment or do not have hypertension should be undertaken to assess the usefulness of the CPBP measurement method in the diagnosis of hypertension.

- The schedule of CPBP measurements in our studies was set arbitrarily, as there is no recommendation in this regard. It is necessary to properly define the number, timing, and frequency of visits to the community pharmacy that allow obtaining a BP value as valid or close to "true/habitual" BP as possible

- The CPBP measurements were taken by the same pharmacist in each community pharmacy. This method is distinct from a patient measuring his or her BP in the community pharmacy without any pharmacist supervision using selfattended BP monitors. Additionally, different pharmacists or pharmacy technicians taking CPBP measurements in the same pharmacy may have some impact on the results.

- Patients with arrhythmia were excluded from our studies, as oscillometric devices may not be able to give accurate BP measurements for this condition. Thus, our findings are not applicable to this group of patients. The limitations of using these oscillometric devices are inherent to the devices themselves and are present regardless of the location of measurement. It is becoming increasingly necessary that scientific societies, standardization bodies, and manufacturers address and work to improve this issue. ${ }^{24}$ As this development is taking place, community pharmacists should take into account the use of other types of devices to measure the CPBP (e.g., aneroid sphygmomanometers).

- The community pharmacies that collaborated in the studies were all from Spain. Depending on the country and on the health system model, community pharmacies may have different characteristics (e.g., business model, staff training, reimbursement for services, staff availability, and patient confidence) that could significantly affect the availability or the ability of the CPBP measurement method and, therefore, the generalization of the results. In our opinion, our methods (using trained pharmacists and validated equipment) are relatively simple and could be exported to any community pharmacy. However, they should be tested under the specific conditions of other countries.
- There is no evidence showing which CPBP values should be considered as the optimal target for drug treatment or for the diagnosis of hypertension. We have assumed the thresholds used in the clinical setting as reasonable points of reference (systolic BP less than $140 \mathrm{~mm} \mathrm{Hg}$ and diastolic BP less than $90 \mathrm{~mm} \mathrm{Hg}$ ). This matter should be studied in depth, as it is possible that normal CPBP values may be different from those defined in the clinical setting, even similar to those established for HBPM or daytime ABPM (systolic BP less than $135 \mathrm{~mm} \mathrm{Hg}$ and diastolic BP less than $85 \mathrm{~mm} \mathrm{Hg}){ }^{17}$

In the future, we hope that these and other issues can be resolved. Thus, it will be possible to clarify the usefulness of the CPBP measurement method in the management of hypertension and to establish clear recommendations to guide decision making based on these measurements.

\section{Authors}

DANIEL SABATER-HERNÁNDEZ, PharmD, PhD, is Research Project Supervisor; JOSE SENDRA-LILLO, PharmD, PhD, is Research Associate; MARÍA JOSÉ FAUS, PharmD, PhD, is Professor and Director; and FERNANDO MARTÍNEZ-MARTÍNEZ, PharmD, PhD, is Professor and Sub-Director, Pharmaceutical Care Department (Cátedra de Atención Farmacéutica), University of Granada, Granada, Spain. ALEJANDRO DE LA SIERRA, MD, $\mathrm{PhD}$, is Professor, Department of Internal Medicine, Hospital Mutua Terrassa, University of Barcelona, Barcelona, Spain.

AUTHOR CORRESPONDENCE: Daniel Sabater-Hernández, PharmD, PhD, Pharmaceutical Care Department (Cátedra de Atención Farmacéutica), University of Granada, Facultad de Farmacia, Campus Universitario de Cartuja s/n. C.P. 18071, Granada, Spain. Telephone: +34 639 838452; E-mail: dsabater@gmail.com.

\section{DISCLOSURES}

Lacer Farma (Barcelona, Spain) supplied the devices for the MEPAFAR study. Lacer Farma markets a range of blood pressure monitoring devices for health professionals and patients and automated systems for recording and reporting blood pressure measurements. Sabater-Hernández reports receipt of consulting fees and payment for lectures/service bureau from Lacer Farma. De la Sierra and Sabater-Hernández report receipt of compensation for travel and meeting expenses from Lacer Farma. The other authors report no financial or other potential conflicts of interest related to the subject of this article.

Concept and design of the MEPAFAR and Palmera studies were performed by Sabater-Hernández and Sendra-Lillo, respectively, with the assistance of José Faus and Martínez-Martínez. Sabater-Hernández was the supervisor of the Palmera study, and de la Sierra was the supervisor of both studies. Data for the studies were collected by Sendra-Lillo and community pharmacists participating in the MEPAFAR and Palmera studies: Hernández-Peña, SabaterDíaz, Artiles-Campelo, Jorge-Rodríguez, García-Morales, Santana-Pérez, Merino-Barber, Díaz-Merino, Artíles-Ruano, Contardi-Lista, and GarcíaRodríguez. This article was written primarily by Sabater-Hernández and de la Sierra and was revised by Sendra-Lillo, José Faus, and Martínez-Martínez. 


\section{REFERENCES}

1. Pickering TG, Gerin W, Schwartz AR. What is the white-coat effect and how should it be measured? Blood Press Monit. 2002;7(6):293-300.

2. Palatini P. Ambulatory and home blood pressure measurement: complementary rather than competitive methods. Hypertension. 2012;59(1):2-4.

3. Sega R, Facchetti R, Bombelli M, et al. Prognostic value of ambulatory and home blood pressures compared with office blood pressure in the general population: follow-up results from the Pressioni Arteriose Monitorate e Loro Associazioni (PAMELA) study. Circulation. 2005;111(14):1777-83. Available at: http://circ.ahajournals.org/content/111/14/1777.full.pdf+html. Accessed June 27, 2012.

4. Fagard RH, Van Den Broeke C, De Cort P. Prognostic significance of blood pressure measured in the office, at home and during ambulatory monitoring in older patients in general practice. J Hum Hypertens. 2005;19(10):801-07. Available at: http://www.nature.com/jhh/journal/v19/ n10/pdf/1001903a.pdf. Accessed June 27, 2012.

5. Niiranen TJ, Hänninen MR, Johansson J, Reunanen A, Jula AM. Homemeasured blood pressure is a stronger predictor of cardiovascular risk than office blood pressure: the Finn-Home study. Hypertension. 2010;55(6):1346-51.

6. Mancia G, De Backer G, Dominiczak A, et al. 2007 Guidelines for the Management of Arterial Hypertension: The Task Force for the Management of Arterial Hypertension of the European Society of Hypertension (ESH) and of the European Society of Cardiology (ESC). Eur Heart J. 2007;28(12):1462536. Available at: http://eurheartj.oxfordjournals.org/content/28/12/1462. long. Accessed June 27, 2012.

7. Parati G, Stergiou GS, Asmar R, et al. European Society of Hypertension practice guidelines for home blood pressure monitoring. J Hum Hypertens. 2010;24(12):779-85.

8. National Clinical Guideline Centre. Hypertension: the clinical management of primary hypertension in adults. Clinical guideline 127: methods, evidence, and recommendations. August 2011. Available at: http://www.nice org.uk/nicemedia/live/13561/56007/56007.pdf. Accessed June 27, 2012.

9. Pickering TG, Miller NH, Ogedegbe G, Krakoff LR, Artinian NT, Goff D. Call to action on use and reimbursement for home blood pressure monitoring: a joint scientific statement from the American Heart Association, American Society of Hypertension, and Preventive Cardiovascular Nurses Association. Hypertension. 2008;52(1):10-29. Available at: http://www.ncbi.nlm.nih.gov/ pmc/articles/PMC2989415/?tool=pubmed. Accessed June 27, 2012

10. Viera AJ, Cohen LW, Mitchell CM, Sloane PD. Hypertensive patients' use of blood pressure monitors stationed in pharmacies and other locations: a cross-sectional mail survey. BMC Health Serv Res. 2008;8:216. Available at: http://www.biomedcentral.com/1472-6963/8/216. Accessed June 27, 2012

11. Chan AHW, Campbell NR, Lewanczuk RZ, Semchuk W, Thompson A, Tsuyuki R; the Canadian Hypertension Education Program Implementation Task Force. 2008 Canadian Hypertension Education Program Guidelines for the management of hypertension by pharmacists. Can Pharm J. 2008;141(6):327-31. Available at: http://www.cpjournal.ca/doi/ pdf/10.3821/1913-701X-141.6.327. Accessed June 27, 2012.

12. Sabater-Hernández D, de la Sierra A, Bellver-Monzó O, et al. Action guide for the community pharmacist in patients with hypertension and cardiovascular risk. Consensus document (condensed version). Hipertens riesgo vasc. 2011;28(5-6):169-81. Available at: http://apps.elsevier.es/ watermark/ctl_servlet?_f=10\&pident_articulo $=90040578 \&$ \&ident usuario $=0 \&$ pcontactid $=\&$ pident_revista $=67 \&$ ty $=15 \&$ accion $=$ L\&origen $=$ els evier $\&$ web $=$ www.elsevier.es $\& l a n=$ es $\&$ fichero $=67 \mathrm{v} 28 \mathrm{n} 05 \mathrm{a} 90040578 \mathrm{pdf0} 01$ pdf. Accessed June 27, 2012
13. Sabater-Hernández D, Azpilicueta I, Sánchez-Villegas P, Amariles P, Baena MI, Faus MJ. Clinical value of blood pressure measurement in the community pharmacy. Pharm World Sci. 2010;32(5):552-58.

14. Zaninelli A, Parati G, Cricelli C, et al.; MARTE Investigators. Office and 24-h ambulatory blood pressure control by treatment in general practice: the 'Monitoraggio della pressione ARteriosa nella medicina TErritoriale' study. J Hypertens. 2010;28(5):910-17.

15. Hänninen MR, Niiranen TJ, Puukka PJ, Jula AM. Comparison of home and ambulatory blood pressure measurement in the diagnosis of masked hypertension. J Hypertens. 2010;28(4):709-14.

16. Zaki R, Bulgiba A, Ismail R, Ismail NA. Statistical methods used to test for agreement of medical instruments measuring continuous variables in method comparison studies: a systematic review. PLoS One. 2012;7(5): e37908. Available at: http://www.ncbi.nlm.nih.gov/pmc/articles/ PMC3360667/?tool=pubmed. Accessed June 27, 2012.

17. Sabater-Hernández D, de la Sierra A, Sánchez-Villegas P, Santana-Pérez FM, Merino-Barber L, Faus MJ. Agreement between community pharmacy and ambulatory and home blood pressure measurement methods to assess the effectiveness of antihypertensive treatment: the MEPAFAR study. J Clin Hypertens (Greenwich). 2012;14(4):236-44. Available at: http://onlinelibrary. wiley.com/doi/10.1111/j.1751-7176.2012.00598.x/pdf. Accessed June 27, 2012.

18. Sabater-Hernández D, de la Sierra A, Sánchez-Villegas P, Baena MI, Amariles P, Faus MJ. Magnitude of the white-coat effect in the community pharmacy setting: the MEPAFAR study. Am J Hypertens. 2011;24(8):887-92.

19. Sendra-Lillo J, Sabater-Hernández D, Sendra-Ortolá A, MartínezMartínez F. Agreement between community pharmacy, physician's office, and home blood pressure measurement methods: the Palmera study. Am J Hypertens. 2012;25(3):290-96.

20. Sendra-Lillo J, Sabater-Hernández D, Sendra-Ortola A, MartínezMartínez F. Comparison of the white-coat effect in community pharmacy versus the physician's office: the Palmera study. Blood Press Monit. 2011;16(2):62-66

21. Sabater-Hernández D, Sánchez-Villegas P, Lacampa P, Artiles-Campelo A, Jorge-Rodríguez ME, Faus MJ. Evaluation of the hypertensive state in treated patients: selection of appropriate blood pressure measurements per visit to the community pharmacy. Blood Press Monit. 2011;16(3):103-10.

22. Sabater-Hernández D, Sánchez-Villegas P, García-Corpas JP, Amariles P, Sendra-Lillo J, Faus MJ. Predictors of the community pharmacy white-coat effect in treated hypertensive patients. The MEPAFAR study. Int J Clin Pharm. 2011;33(3):582-89.

23. Stergiou GS, Parati G, Asmar R, O’Brien E. Requirements for professional office blood pressure monitors. J Hypertens. 2012;30(3):537-42.

24. Palatini P, Frick GN. Techniques for self-measurement of blood pressure: limitations and needs for future research. J Clin Hypertens (Greenwich). 2012;14(3):139-43. Available at: http://onlinelibrary.wiley.com/doi/10.1111/ j.1751-7176.2011.00586.x/pdf. Accessed June 29, 2012.

25. Amariles P, Sabater-Hernández D, García-Jiménez E, et al. Effectiveness of Dader Method for pharmaceutical care on control of blood pressure and total cholesterol in outpatients with cardiovascular disease or cardiovascular risk: the EMDADER-CV randomized controlled trial. J Manag Care Pharm. 2012;18(4):311-23. Available at: http://www.amcp.org/JMCP/2012/ May/15166/1033.html.

26. Myers MG, Godwin M, Dawes M, et al. Conventional versus automated measurement of blood pressure in primary care patients with systolic hypertension: randomised parallel design controlled trial. BMJ. 2011;342:d286. Available at: http://www.ncbi.nlm.nih.gov/pmc/articles/ PMC3034423/?tool=pubmed. Accessed June 27, 2012. 